\title{
RESEARCH
}

\section{Correlation Between Pharmacy Students' Implicit Bias Scores, Explicit Bias Scores, and Responses to Clinical Cases}

\author{
Jennifer Santee, PharmD, ${ }^{a}$ Kylie Barnes, PharmD, ${ }^{a}$ Nancy Borja-Hart, PharmD, ${ }^{b}$ An-Lin Cheng, PhD, ${ }^{c}$ Juanita \\ Draime, PharmD, RPh, ${ }^{\mathrm{d}}$ Akesha Edwards, PhD, PharmD, ${ }^{\mathrm{e}}$ Nkem Nonyel, PharmD, MPH, ${ }^{\mathrm{f}}$ Mark Sawkin, \\ PharmD $^{\mathrm{a}}$ \\ ${ }^{a}$ University of Missouri - Kansas City, School of Pharmacy, Kansas City, Missouri \\ ${ }^{\mathrm{b}}$ University of Tennessee Health Science Center, College of Pharmacy, Memphis, Tennessee \\ ${ }^{c}$ University of Missouri - Kansas City, School of Medicine, Kansas City, Missouri \\ ${ }^{\mathrm{d}}$ Cedarville University, School of Pharmacy, Cedarville, Ohio \\ ${ }^{\mathrm{e}}$ University of Findlay, College of Pharmacy, Findlay, Ohio \\ ${ }^{\mathrm{f}}$ University of Maryland Eastern Shore, School of Pharmacy, Princess Anne, Maryland
}

Corresponding Author: Jennifer Santee, University of Missouri - Kansas City, School of Pharmacy, 2464 Charlotte St., Kansas City, MO. Tel: 816-520-8391. Email: $\underline{\text { santeej@umkc.edu }}$

Submitted February 8, 2021; accepted June 2, 2021; ePublished June 2021

Objective. The purpose of this study is to identify the extent of implicit and explicit bias in a sample of pharmacy students and to determine if there is an association between implicit bias, explicit bias, and responses to clinical cases. Methods. Investigators sent links to two online surveys to students. In the first survey, students responded to two clinical cases. Students were presented with a picture of a white or Black patient with each clinical case. Students indicated on the second survey their level of racial implicit bias as assessed by the Harvard Implicit Association Test and their level of racial explicit bias. Pearson's correlation was used to determine the correlation between bias and responses to the clinical cases.

Results. Three hundred and fifty-seven first, second, and third year of pharmacy students responded to both surveys (response rate 52\%). The students presented with the picture of a Black patient rated the patient's pain and the reliability of the patient's family as higher than students presented with the picture of a white patient. Students had more negative implicit and explicit bias towards Black patients. Neither implicit nor explicit bias correlated with student responses to the clinical cases.

Conclusion. Evidence of slight to moderate negative implicit bias and slight negative explicit bias towards Black patients does exist for pharmacy students. Future studies that include a more representative student population and heighten the stakes of the clinical scenario should be done to investigate a possible correlation between bias and clinical behaviors.

Keywords: bias; implicit; race; prejudice

\section{INTRODUCTION}

Health disparities are evident when comparing care between different races. Health disparities are defined as "...preventable differences in the burden of disease, injury, violence, or opportunities to achieve optimal health that are experienced by socially disadvantaged populations." "Forty-two percent of Agency for Health care Research and Quality measures were worse for Black vs white patients in 2014-2016, and these include the number of patients with an adverse event to a low molecular weight heparin, number of deaths in hospitalized patients with expected low mortality, number of hospitalized patients with an adverse event to a hypoglycemic agent. ${ }^{2}$ Discrimination has resulted in these health disparities. ${ }^{3}$

Discrimination may be the result of bias, which may be explicit or implicit. Explicit bias is a situation where an individual recognizes that he or she holds negative feelings or beliefs towards one group over another or favors a certain group unlike implicit bias, where an individual is unaware of negative feelings, beliefs, or preferences. ${ }^{4}$ Several investigators have identified an association between implicit bias and differential treatment by practicing health care providers. ${ }^{5,6}$ Physicians with a pro-white bias were more likely to agree with prescribing narcotics for white patients than 
for Black patients. ${ }^{5}$ Physicians with a pro-white bias were also more likely to treat white patients than Black patients with thrombolytics. ${ }^{6}$ The association between implicit bias and differential treatment was seen even when the association between explicit bias and differential treatment didn't exist. ${ }^{6}$ These unconscious biases may be evident to patients as well. Black patients were less likely to perceive that the clinician respected them, less likely to respect the clinician, had less confidence in the clinician, and were less likely to recommend the clinician to others when the clinician scored at a higher level of implicit positive bias for white patients. ${ }^{7}$

Other investigators, however, have not observed a correlation between bias and clinical decisions. No association was found between implicit bias and pediatrician treatment decisions regarding urinary tract infections, attention deficit disorder, and asthma. ${ }^{5}$ First year medical students were asked to rate a patient's pain and assess the reliability of information provided by a patient's family using clinical vignettes. ${ }^{8}$ Interestingly, students with a pro-white bias did not respond any differently to the vignettes when compared to students without bias, or to students with a pro-Black bias. Although many pharmacy school programs incorporate the topic of cultural competence/cultural sensitivity within their curricula, very few publications discuss increasing student awareness of implicit bias or discussing methods to reduce bias. ${ }^{9-18}$ The purpose of this study is to identify the extent of implicit and explicit bias in a sample of Doctor of Pharmacy (PharmD) students and to determine if there is an association between implicit bias, explicit bias, and responses to clinical cases assessing patients of a different race.

\section{METHODS}

This cross-sectional study was conducted with Doctor of Pharmacy students from six schools/colleges of pharmacy within the United States. Each of the participating Colleges or Schools of Pharmacy obtained an Institutional Review Board (IRB) approval prior to participating in this study, and their IRB approval letters were submitted to the University of Missouri - Kansas City (UMKC) IRB. This study was determined to be exempt by the UMKC IRB. The participating institutions and student populations were selected based on convenience sampling and interest in the project to provide a sufficient sample size to detect a correlation. Demographics of each institution are provided in Table 1. A total of 688 first, second, and third year students enrolled in a social/behavioral/administrative science course within each institution's required curriculum were invited to participate in the study from April 2019 through April 2020. A verbal consent script was read to students prior to the surveys being administered. Participants completed the survey while participating in class. Only those students who consented participated in the study. There were no consequences for not participating in the study. Participants answered questions anonymously.

The first survey collected demographic information from the subjects and asked the participants to respond to two cases. The first case was a 48-year-old male presenting to the emergency department after being assaulted. The second case was a 35-year-old female, two days postoperative presenting with symptoms suggesting delirium tremens.

Investigators provided a picture of the patient for each case. Some participants received a picture of a Black patient for a case, whereas other participants received a picture of a white patient for the same case. Students were randomly assigned which picture they received at one school. For the remaining schools, student names were arranged alphabetically and the students in the first half of the class received a picture of a white patient for the first case while the students in the second half of the class received a picture of a Black patient for the first case. The race of the patient was reversed for the second case. The camera angle, the distance between the patient and the camera, the patient's facial expression, and the patient's position (lying in bed) were the same regardless of the patient's race. The text describing the patient's history of present illness and the questions regarding each case were the same regardless of the race of the patient. The participants indicated the race of both patients in the first survey. The student also rated the patient's pain for the first case on a scale of 1-10 (1 being the least pain and 10 being the worst pain imaginable) and the reliability of information provided by the patient's family for the second case on a scale of one to five ( 1 =very reliable, $2=$ reliable, $3=$ uncertain, $4=$ unreliable, $5=$ very unreliable). This portion of the survey was adapted from a previous study on implicit bias. ${ }^{8}$

Immediately following the first survey, investigators then instructed the participants to complete the Harvard Race Implicit Association Test (IAT). The Race IAT identifies unconscious bias by measuring how long it takes an individual to group a picture of a person of a certain race with words that have either a positive or a negative connotation. The theory behind the Race IAT is that those with negative bias towards a certain race will take longer to group the picture of a person of that race with a positive word and vice versa. Those completing the Race IAT are notified if they have a strong, moderate, or slight preference for white or Black people or if they have no preference. The predictive validity of the IAT has been demonstrated in previous literature. ${ }^{19}$ 
Immediately following completion of the Race IAT, the investigators provided the participants with a link to a second survey in which the participants indicated the results from their Race IAT, their preference for white vs Black persons (strongly prefer, moderately prefer, slightly prefer, or no preference), and how warm or cold they felt towards Black vs white persons using a scale of 0 to 10; 0 represented the coldest feelings, 5 represented neutral feelings, and 10 represented the warmest feelings. The Race IAT results and the explicit preferences were translated into rankings from 1 (strong preference for white people) to 4 (no preference for either race) to 7 (strong preference for Black people). Survey responses were linked using a unique identifier code. Participants that completed both surveys and whose responses from the first survey could be linked to the second survey were included in the statistical analysis. Descriptive statistics were used to summarize the extent of implicit bias, explicit bias, and responses to clinical cases. Mann-Whitney test was used to compare results between various sub-groups of participants. Pearson's correlation was used to determine the correlation between bias scores and responses to clinical cases.

\section{RESULTS}

Three hundred and fifty-seven (357) participants (overall response rate 52\%) responded to both surveys and provided a unique identifier code that allowed for their responses to the first survey to be linked to their responses to the second survey. Table 2 summarizes the demographic data of these respondents. The majority of students were white, female, 22-25 years of age, attending pharmacy school in the Midwest, and enrolled in the first year of pharmacy school. Two hundred and seventeen subjects were presented with a picture of a Black patient and 139 subjects were presented with a picture of a white patient for the first case. The median pain rating score given by students presented with a picture of a Black patient was higher than the average pain rating score given by students presented with a picture of a white patient (7 (IQR:6-8) vs 6 (IQR:5-7), $p<.05$ ).

One hundred and thirty-two students (132) were presented with a Black patient and 225 students were presented with a picture of a white patient for the second case. Subjects presented with a Black patient rated the information provided by the patient's family as more reliable than the students presented with a white patient (2 (IQR:2-3) vs 3 (IQR:3-4), $p<.05$ ).

The mean rank for Race IAT scores was 2.76, indicating that most subjects had a slight to moderate implicit preference for white people. The mean rank of explicit preference was 3.73, indicating that most subjects had a slight explicit preference for white people. The mean rankings of warmth towards Black and white people was 7.65 and 7.76 respectively, indicating most subjects had generally warm feelings for both Black and white people. The extent of implicit and explicit bias did not differ between students enrolled in their first or second year and students enrolled in their third year or between students who were shown a picture of a Black patient and students who were shown a picture of a white patient ( $p>$.05). The extent of implicit bias and level of warmth towards European Americans and African Americans did not differ between students enrolled in an urban vs rural school $(p>.05)$. The extent of explicit bias was statistically different between students enrolled in an urban vs rural school $(p<.05)$ but the difference was not meaningful (median was 4 for both urban and rural students). The extent of how warm students felt towards European Americans did not differ between Black and non-Black students. Non-black students compared to Black students had more implicit preference for European Americans (2 vs 4, $p<.05$ ), more explicit preference for European Americans (4 vs 5, p<0.05), and less warmth for African Americans (8 vs $9, p<.05)$.

Table 3 provides the correlation between implicit bias, explicit bias, and responses to clinical cases. Results from the Race IAT, measures of explicit preference, measures of warmth towards white people, and measures of warmth towards Black people did not demonstrate a significant correlation with ratings of pain or family reliability provided for the patient cases.

\section{DISCUSSION}

While pain scores and family reliability scores were higher for participants presented with a Black patient than for participants presented with a white patient, one might question the clinical significance of the differences. The differences were less than one point and it would be unlikely for a respondent noting a difference to note a change less than one point. Although health professionals with more negative implicit bias towards Black patients were less likely to prescribe a narcotic to Black patients in a different study, ${ }^{5}$ the overall pain rating was higher for the Black patient and a correlation didn't exist between implicit bias and ratings of pain in this study. The lack of correlation with bias and pain scores as well as bias and reliability scores does not allow for the conclusion that health professional bias does not have an impact on patient care, however. Reliance on implicit bias may be stronger when the provider is faced with cases where they 
must make quick, difficult decisions, with incomplete data. ${ }^{20}$ Since participants answered the questions anonymously in a classroom session, our vignettes were likely less stress inducing than having to make a decision with a real patient where the decision will have a greater impact.

Several limitations exist for this study. The results may not be generalizable to the whole pharmacy student population given differences between sample and population demographics. The sample of respondents is similar to all pharmacy schools accredited by the Accreditation Council for Pharmacy Education with respect to the proportion of female students but has a higher percentage of white students and lower percentage of Black students. ${ }^{21}$ Demographics relating to socioeconomic status and sexual orientation were not collected from the participants and may affect the level of bias. Most of sample included first year students so whether the results can be applied to students enrolled in later years is uncertain. The number of participants were impacted by technical difficulties accessing and completing the surveys at one site. Several students were unable to complete both surveys within the allotted time. No identifiable information was collected from the participants but still participants may have been compelled to provide more socially acceptable responses than truthful responses, leading to an underestimation of bias. Validity of the measures of explicit bias have not been investigated within pharmacy students. Lastly, schools and colleges of pharmacy differ as to when and to what extent cultural sensitivity is taught within their curriculum which could have an impact on the magnitude of student implicit and explicit bias and the correlation between bias and clinical decisions. It should be noted that, despite the effect of under-estimation, pro-white bias was indeed reported. Further investigation of this bias is warranted.

\section{CONCLUSION}

Bias towards Black patients does exist for pharmacy students. Future studies that include a more representative student population and heighten the stakes of the clinical scenario should be done to investigate a possible correlation between bias and clinical behaviors.

\section{REFERENCES}

1. Centers for Disease Control and Prevention (CDC). 2018. Health Disparities. Accessed on 09/06/2020 from https://www.cdcgov/healthyyouth/disparities/index.htm. Last reviewed on August 17, 2018

2. Agency for Healthcare Research and Quality. 2017. National Healthcare Quality and Disparities Report. Rockville, MD:. AHRQ Pub. No. 18-0033-EF.

3. IOM (Institute of Medicine). 2012. How far have we come in reducing health disparities?: Progress since 2000: Workshop Summary. Washington, DC: The National Press.

4. Davido JF, Gaertner SL. Aversive racism and selection decisions: 1989 and 1999. Psychological Science. 2000;11(4):315-319.

5. Sabin JA, Greenwald AG. The influence of implicit bias on treatment recommendations for 4 common pediatric conditions: Pain, urinary tract infection, attention deficit disorder, and asthma. American Journal of Public Health. 2012;102(5):988-995.

6. Green AR, Carney DR, Pallin DJ, Ngo LH, Raymond KL, Iezzoni LI, Banaji MR. Implicit bias among physicians and its prediction of thrombolysis decisions for black and white patients. Journal of General Internal Medicine 2007;22:1231-1238.

7. Cooper LA, Roter DL, Carson KA, Beach MC, Sabin JA, Greenwald AG, Inui TS. The associations of clinicians' implicit attitudes about race with medical visit communication and patient ratings of interpersonal care. American Journal of Public Health 2012;102(5):979-987.

8. Haider AH, Sexton J, Sriram N, Cooper LA, Efron DT, Swoboda S, Villegas CV, Haut ER, Bonds M, Pronovost PJ, Lipsett PA, Freishlag JA, Cornwell EE. Association of unconscious race and social class bias with vignettebased clinical assessments by medical students. JAMA. 2011;306(9):942-951.

9. Poirier TI, Butler LM, Radhika D, Gupchup GV, Santanello C, Lynch C. A cultural competency course for pharmacy students. Am J Pharm Educ 2009;73(4):Article 81.

10. Haack S, Phillips C. Teaching cultural competency through a pharmacy skills and application course series. Am J Pharm Educ 2012;76(2):Article 27.

11. Westberg SM, Bumgardner MA, Lind PR. Enhancing cultural competency in a college of pharmacy curriculum. Am J Pharm Educ 2005;69(5):Article 82.

12. Vyas D, Caligiuri FJ. Reinforcing cultural competency concepts during introductory pharmacy practice experiences. Am J Pharm Educ 2010;74(7):Article 129. 
13. Sales I, Jonkman L, Connor S, Hall D. A comparison of educational interventions to enhance cultural competency in pharmacy students. Am J Pharm Educ 2013;77(4):Article 76.

14. Muzumdar JM, Holiday-Goodman M, Black C. Cultural competence knowledge and confidence after classroom activities. Am J Pharm Educ 2010;74(8):Article 150.

15. Wilby KJ, Taylor J, Khalifa SI, Jorgenson D. A course-based cross-cultural interaction among pharmacy students in Qatar and Canada. Am J Pharm Educ 2015;79(2):Article 26.

16. Mathews JL, Parkhill AL, Schlehofer DA, Starr MJ, Barnett S. Role-reversal exercise with deaf strong hospital to teach communication competency and cultural awareness. Am J Pharm Educ 2011;75(3):Article 53.

17. Haack S. Engaging pharmacy students with diverse patient populations to improve cultural competence. Am $J$ Pharm Educ 2008;72(5):Article 124.

18. Avants ND, Weed E, Connelly C, et a. Qualitative Analysis of Student Pharmacists' Reflection of Harvard Race Implicit Bias Association Test. 2018. Curr Pharm Teach Learn; 10(5): 611-617. doi:10.1016/jcptl.2018.02.002

19. Greenwald AG, Uhlmann EL, Poehlman TA, Banaji MR. Understanding and using the Implicit Association Test: III. Meta-analysis of predictive validity. Journal of Personality and Social Psychology. 2009;97(1):17-41.

20. Burgess DJ, van Ryn M, Crowley-Makota M, Malat J. Understanding the provider contribution to race/ethnicity disparities in pain treatment: Insights from dual process models of stereotyping. Pain Medicine 2006;7(2):119134.

21. American Association of Colleges of Pharmacy. Fall 2019 Enrollments: Profile of Pharmacy Students. https://www.aacp.org/sites/default/files/2020-05/fall-2019-pps-enrollments.pdf, accessed June 22, 2020. 
Table 1. Characteristics of Participating Schools/Colleges of Pharmacy

\begin{tabular}{|c|c|c|c|c|c|c|c|}
\hline $\begin{array}{c}\text { Name of } \\
\text { College/School }\end{array}$ & $\begin{array}{c}\text { Total } \\
\text { Enrollmen } \\
\text { t (2019) }\end{array}$ & $\begin{array}{c}\text { Year of } \\
\text { Students } \\
\text { Participatin } \\
\text { g in the } \\
\text { Study }\end{array}$ & 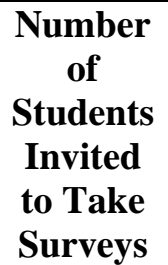 & $\begin{array}{c}\text { Respons } \\
\text { e Rate } \\
\text { per } \\
\text { School } \\
(\%)\end{array}$ & $\begin{array}{c}\text { Urban } \\
\text { Location } \\
*\end{array}$ & $\begin{array}{l}\text { Public } \\
\text { or } \\
\text { Privat } \\
\text { e }\end{array}$ & $\operatorname{Region}^{\mathrm{a}}$ \\
\hline $\begin{array}{l}\text { Cedarville University } \\
\text { Manchester }\end{array}$ & 183 & P1 & 36 & 81 & No & Private & Midwest \\
\hline University & 280 & $\mathrm{P} 1, \mathrm{P} 2, \mathrm{P} 3$ & 202 & 68 & No & Private & Midwest \\
\hline $\begin{array}{l}\text { University of Findlay } \\
\text { University of } \\
\text { Maryland Eastern }\end{array}$ & 306 & P3 & 62 & 95 & No & Private & Midwest \\
\hline $\begin{array}{l}\text { Shore } \\
\text { University of } \\
\text { Missouri - Kansas }\end{array}$ & 142 & P1 & 32 & 63 & No & Public & Northeast \\
\hline $\begin{array}{l}\text { City } \\
\text { University of }\end{array}$ & 583 & P1 & 153 & 82 & Yes & Public & Midwest \\
\hline & 725 & P1 & 203 & 18 & Yes & Public & South \\
\hline
\end{tabular}

${ }^{a}$ As defined by PHARMCAS, except for the location of the students at the University of Tennessee, where all invited students were on an urban campus

$\mathrm{P} 1=$ first professional year; $\mathrm{P} 2=$ second professional year; $\mathrm{P} 3=$ third professional year 
Table 2. Demographics of Respondents

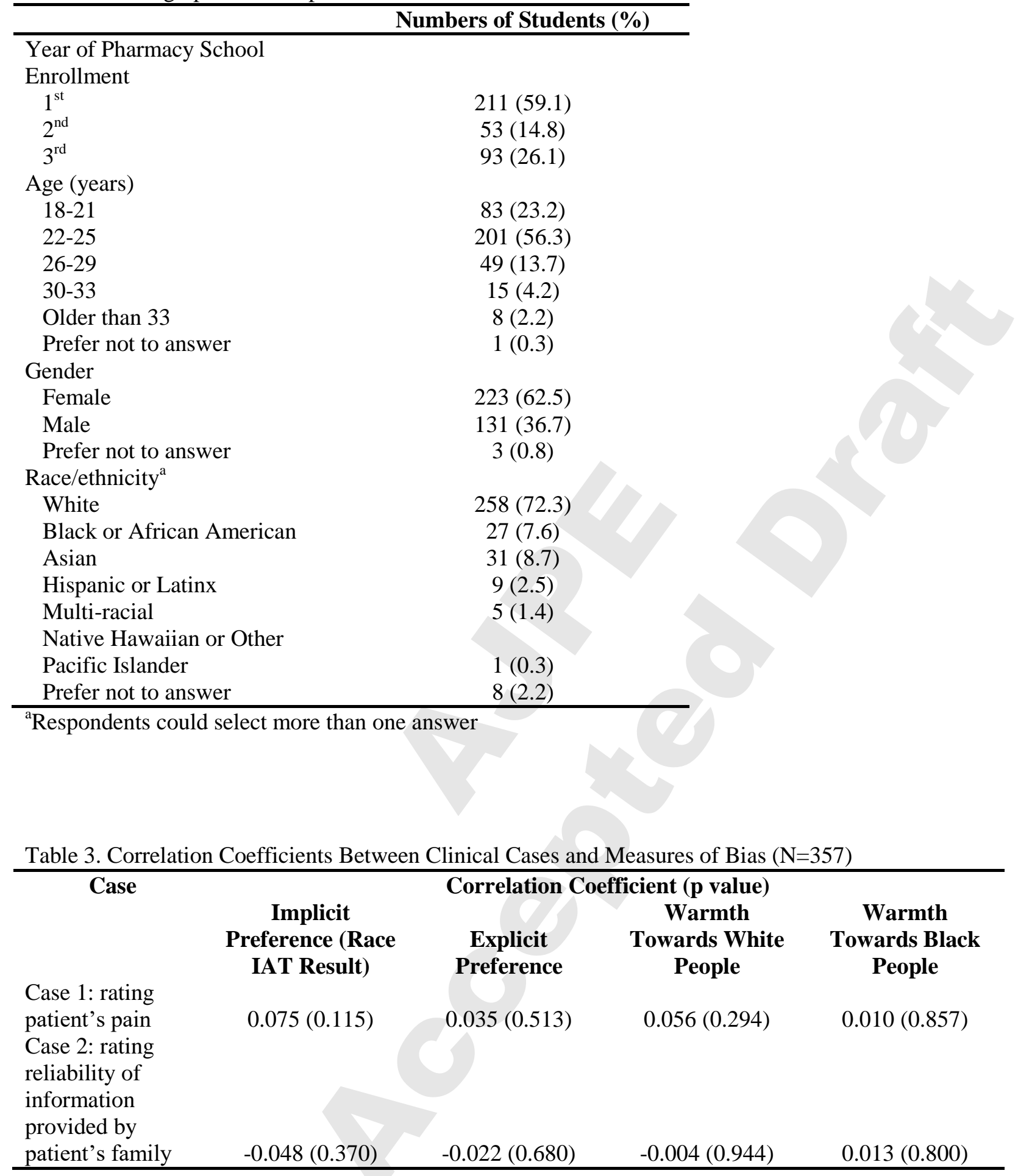

